\title{
A Commentary on Identification of novel MLC1 mutations in Chinese patients with megalencephalic leukoencephalopathy with subcortical cysts (MLC)
}

\author{
Ilja Boor
}

Journal of Human Genetics (2011) 56, 173; doi:10.1038/jhg.2011.5; published online 10 February 2011

$\mathrm{M}$ egalencephalic leukoencephalopathy with subcortical cysts (MLC, OMIM 604004) is a rare neurological disorder in children with an autosomal recessive mode of inheritance. ${ }^{1}$ Characteristics for the disease are the development of macrocephaly within the first year of life and the delayed onset of slow progressive motor deterioration with ataxia and mild spasticity. In most children this leads to wheelchair dependency in their teens. Mental capacities, however, are relatively spared. Magnetic resonance imaging is diagnostic and typically shows diffuse cerebral white matter signal abnormalities of the affected white matter, and the characteristic subcortical cysts in anterior temporal and frontopariental areas. ${ }^{1}$ In time, the white matter swelling decreases and cerebral atrophy proceeds, whereas the subcortical cysts increase in size and number. Histopathological and electron microscopic examination of a brain biopsy from an MLC patient reveals that the white matter swelling was caused by the presence of countless vacuoles between the outer lamellae of myelin sheaths. ${ }^{2}$

In 2000, Topçu et al. ${ }^{3}$ showed that the MLC1 gene is located on chromosome 22qtel. Subsequently, the MLC1 gene was identified in 2001 by Leegwater et al. ${ }^{4}$ It should be noted that in about $25 \%$ of the patients with typical clinical and magnetic resonance imaging picture, no $M L C 1$ mutations are found. Several of the families, in which no mutations are found, also do not show linkage with the MLC1 locus, which

Dr I Boor is at the Department of Pediatrics/Child Neurology, VU University Medical Center, De Boelelaan 1085, $1081 \mathrm{HV}$, Amsterdam, The Netherlands.

E-mail: ilja.boor@vumc.nl suggests at least one other gene to be involved in MLC. ${ }^{4}$

The MLC1 protein is specifically expressed in distal processes of astrocytes called endfeet. $^{5,6}$ This specific localization, the number of transmembrane domains, together with a weak insignificant homology between MLC1 and several transporters or channels suggests a possible transporter function of the MLC1 protein. At present functional data are still lacking.

The MLC1 gene consists of 11 coding exons and a first non-coding exon. It encodes a 377-amino-acids plasma membrane protein with eight transmembrane domains and is highly conserved throughout evolution in vertebrates that produce myelin. ${ }^{5}$ Mutations in $M L C 1$ occur throughout the entire coding region and include all types: splice-site, nonsense, and missense mutations, as well as deletions and insertions. Most families have unique mutations, although a founder effect is present in several communities; that is, the Indian Agarwal community, Askehnazi Jews and patients of Japanese origin. ${ }^{7-10}$ Mutation analysis was carried out on Chinese MLC patients for the first time by Wang et al. ${ }^{11}$ This resulted in 10 mutations including five novel missense mutations, one novel deletion and one novel splice-site mutation. This splice site mutation was found in 3 out of 11 patients and the authors claim a founder effect. To confirm a unique $M L C 1$ mutation spectrum in Chinese MLC patients, more systemic screening needs to be preformed in a larger patient population as already suggested by the authors. The mutations identified in the study by Wang et al. ${ }^{11}$ add to the growing list of MLC1 mutations and are helpful for laboratories performing DNA sequencing for diagnostic purposes.
1 Van der Knaap, M. S., Barth, P. G., Stroink, H., van Nieuwenhuizen, O., Arts, W. F., Hoogenraad, F. et al. Leukoencephalopathy with swelling and a discrepantly mild clinical course in eight children. Ann. Neurol. 37, 324-334 (1995).

2 Van der Knaap, M. S., Barth, P. G., Vrensen, G. F. \& Valk, J. Histopathology of an infantile-onset spongiform leukoencephalopathy with a discrepantly mild clinical course. Acta. Neuropathol. 92, 206-212 (1996).

3 Topçu, M., Gartioux, C., Ribierre, F., Yalçinkaya, C., Tokus, E., Oztekin, N. et al. Vacuoliting megalencephalic leukoencephalopathy with subcortical cysts, mapped to chromosome 22qtel. Am. J. Hum. Genet. 66, 733-739 (2000)

4 Leegwater, P. A., Yuan, B. Q., van der Steen, J., Mulders, J., Könst, A. A., Boor, P. K. et al. Mutations of MLC1 (KIAA0027), encoding a putative membrane protein, cause megalencephalic leukoencephalopathy with subcortical cysts. Am. J. Hum. Genet. 68, 831-838 (2001)

5 Boor, P. K., de Groot, K., Waisfisz, Q., Kamphorst, W., Oudejans, C. B., Powers, J. M. et al. MLC1: a novel protein in distal astroglial processes. J. Neuropathol. Exp. Neurol. 64, 412-419 (2005).

6 Teijido, O., Martínez, A., Pusch, M., Zorzano, A., Soriano, E., Del Río, J. A. et al. Localization and functional analyses of the MLC1 protein involved in megalencephalic leukoencephalopathy with subcortical cysts. Hum. Mol. Genet. 13, 2581-2594 (2004).

7 Gorospe, J. R., Singhal, B. S., Kainu, T., Wu, F., Stephan, D., Trent, J. et al. Indian Agarwal megalencephalic leukodystrophy with cysts is caused by a common MLC1 mutation. Neurology. 62, 878-882 (2004).

8 Ben-Zeev, B., Levy-Nissenbaum, E., Lahat, H., Anikster, Y., Shinar, Y., Brand, N. et al. Megalencephalic leukoencephalopathy with subcortical cysts; a founder effect in Israeli patients and a higher than expected carrier rate among Libyan Jews. Hum. Genet. 111, 214-218 (2002).

9 Saijo, H., Nakayama, H., Ezoe, T., Araki, K., Sone, S. Hamaguchi, H. et al. A case of megalencephalic leukoencephalopathy with subcortical cysts (van der Knaap disease): molecular genetic study. Brain. Dev. 25, 362-366 (2003)

10 Leegwater, P. A., Boor, P. K., Yuan, B. Q., van der Steen, J., Visser, A., Könst, A. A. et al. Identification of novel mutations in $\mathrm{MLC} 1$ responsible for megalencephalic leukoencephalopathy with subcortical cysts. Hum. Genet. 110, 279-283 (2002).

11 Wang, J., Shang, J., Wu, Y., Gu, Q., Xiong, H., Ding, C. et al. Identification of novel MLC1 mutations in Chinese patients with megalencephalic leukoencephalopathy with subcortical cysts (MLC). J. Hum. Genet. 56, 138-142 (2011). 